\title{
川西亚高山两种树木不同径级根系腐殖化过程中 胡敏酸和富里酸的累积特征
}

刘 群 ${ }^{1}$ 庄丽燕 ${ }^{1}$ 杨万勤 1,2 倪祥银 ${ }^{1}$ 李婷婷 ${ }^{1}$ 徐振锋 ${ }^{1,2 *}$

${ }^{1}$ 四川农业大学生态林业研究所, 四川省林业生态工程重点实验室, 成都 $611130 ;{ }^{2}$ 四川农业大学高山森林生态系统定位研究站, 长江上游生态安全 协同创新中心，成都 611130

摘 要 根系腐殖化过程中腐殖质的累积是土壤有机质形成和碳吸存的一个重要途径。该文采用调落物袋法, 研究了川西亚 高山粗枝云杉(Picea asperata)和怅江冷杉(Abies faxoniana)两种优势林木 3 个径级根系( $(0-2 、 2-5$ 和 $5-10 \mathrm{~mm}$ )在冬季和生长季胡 敏酸和富里酸累积特征。结果表明: 经过两年的腐殖化, 粗枝云杉和岷江冷杉根系胡敏酸和富里酸含量受径级显著影响, 并 随径级增大而降低。不同径级间富里酸净累积量差异显著, 而胡敏酸净累积量差异不显著; 两个树种间胡敏酸和富里酸含量 和净累积量差异不显著。胡敏酸在冬季降解而在生长季节累积, 其中粗枝云杉 $0-2 、 2-5$ 和 $5-10 \mathrm{~mm}$ 根系净累积量分别为 8.0 、 10.8 和7.6 $\mathrm{g} \cdot \mathrm{kg}^{-1}$, 怅江冷杉分别为 $15.2 、 8.0$ 和7.8 $\mathrm{g} \cdot \mathrm{kg}^{-1}$ 。富里酸总体表现为降解, 其中粗枝云杉 $0-2 、 2-5$ 和 $5-10 \mathrm{~mm}$ 根系降 解量为178.0、166.0和 $118.0 \mathrm{~g} \cdot \mathrm{kg}^{-1}$, 怅江冷杉分别为 $170.0 、 160.0$ 和 $128.0 \mathrm{~g} \cdot \mathrm{kg}^{-1}$ 。根系径级对亚高山森林植物根系腐殖质累积 有显著影响, 而径级影响与分解时期有一定关联。

关键词＼cjkstart胡敏酸; 富里酸; 径级; 根系腐殖化

引用格式: 刘群, 庄丽燕, 杨万勤, 倪祥银, 李婷婷, 徐振锋 (2017). 川西亚高山两种树木不同径级根系腐殖化过程中胡敏酸和富里酸的累积特征. 植 物生态学报, 41, 1251-1261. doi: $10.17521 /$ cjpe.2017.0169

\section{Accumulation of humic acid and fulvic acid during root humification of three diameters of two dominant subalpine trees in western Sichuan, China}

LIU Qun ${ }^{1}$, ZHUANG Li-Yan ${ }^{1}$, YANG Wan-Qin ${ }^{1,2}$, NI Xiang-Yin ${ }^{1}$, LI Ting-Ting ${ }^{1}$, and XU Zhen-Feng ${ }^{1,2^{*}}$

${ }^{1}$ Key Laboratory of Ecological Forestry Engineering of Sichuan Province, Institute of Ecology \& Forest, Sichuan Agricultural University, Chengdu 611130, China; and ${ }^{2}$ Long-Term Research Station of Alpine Forest Ecosystems, Collaborative Innovation Center of Ecological Security in the Upper Reaches of Yangtze River, Chengdu 611130, China

\section{Abstract}

Aims Plant roots store large amount of terrestrial carbon, but little is known about humus formation processes during the decomposing root litter. Compared with coarse roots, fine roots have greater nutrients, which may be favorable to humus formation. The objective of the study was to examine how root diameters affect their humus formation processes.

Methods In this study, in order to examine the accumulation of humic acid and fulvic acid of three root diameter classes (0-2, 2-5 and 5-10 mm) of two subalpine tree species (Abies faxoniana and Picea asperata) on the eastern Qinghai-Xizang Plateau of China, a two-year field experiment was conducted using a litter-bag method. Air-dried roots of A. faxoniana and P. asperata were placed in litterbags and incubated at $10 \mathrm{~cm}$ of soil depth in October 11th, 2013. Duplicate litter bags were collected in May (late winter) and October (late in the growing season) of 2014 and 2015, respectively. Concentrations of humic acid and fulvic acid were measured, and net accumulations were calculated for different periods.

Important findings The concentrations of humic acid and fulvic acid were significantly influenced by root diameter that humic acid and fulvic acid decreased with increase in root diameter. Root diameter had significant effects on the net accumulation of humic acid, but not for the accumulation of fulvic acid. However, there were no significant differences in both humic acid and fulvic acid between A. faxoniana and P. asperata roots. Regardless of tree species, humic acid degraded during the winter but accumulated during the growing season. After two years of decomposition, the net accumulations of humic acid in 0-2, 2-5 and 5-10 mm roots were 8.0, 10.8 and

收稿日期Received: 2017-06-29 接受日期Accepted: 2017-12-02

* 通信作者Author for correspondence (E-mail: sicauxzf@163.com) 
$7.6 \mathrm{~g} \cdot \mathrm{kg}^{-1}$ for P. asperata and $15.2,8.0$ and $7.8 \mathrm{~g} \cdot \mathrm{kg}^{-1}$ for $A$. faxoniana, respectively. Conversely, the degradation of fulvic acid in 0-2, 2-5 and 5-10 mm roots were $178.0,166.0$ and $118.0 \mathrm{~g} \cdot \mathrm{kg}^{-1}$ for $P$. asperata and $170.0,160.0$ and $128.0 \mathrm{~g} \cdot \mathrm{kg}^{-1}$ for A. faxoniana, respectively. Our results suggest that diameter-associated variations in substrate quality could be an important driver for root litter humification in this subalpine forest. Moreover, diameter effect is dependent on decomposition period in this specific area.

Key words humic acid; fulvic acid; diameter size; root humification

Citation: Liu Q, Zhuang LY, Yang WQ, Ni XY, Li TT, Xu ZF (2017). Accumulation of humic acid and fulvic acid during root humification of three diameters of two dominant subalpine trees in western Sichuan, China. Chinese Journal of Plant Ecology, 41, 1251-1261. doi: 10.17521/cjpe.2017.0169

腐殖质是一种结构复杂的高分子有机化合物, 是生物残体在微生物作用下经降解、络合形成的产 物(Stevenson, 1994)。植物残体腐殖化过程中腐殖质 的累积是土壤有机质形成和碳吸存的一个重要途 径。已有研究发现不同有机物料(如稻草)能不同程 度地提高土壤腐殖质含量(Chien et al., 2006; 窦森, 2010)。但这些研究集中于地表植物残体, 而对地下 根系的研究较少。研究表明, 在微生物作用下, 植物 根系木质素及其降解产物(如醌类)氧化生成的化合 物构成腐殖质的芳香环骨架(Amir et al., 2006), 促 进腐殖质累积, 影响土壤腐殖质的性质和结构(Asli \& Neumann, 2010), 对土壤形成、发育具有重要意义 (Abakumov et al., 2013; Berg \& McClaugherty, 2014)。

由于提取方法的限制, 目前腐殖质的研究主要 是胡敏酸和富里酸的研究 (Lehmann \& Kleber, 2015)。已有研究表明, 由于胡敏酸溶于碱而富里酸 溶于酸的性质, 导致腐殖质累积受土壤环境、季节 变化、基质品质和微生物等综合因素的影响 (Prescott et al., 2000; Ponge \& Chevalier, 2006)。在同 一气候条件下, 根系分解主要受自身化学性质影响 (Silver \& Miya, 2001)。不同物种、不同直径的根系 化学组分差异显著(靳贝贝和国庆喜, 2013; Makita et al., 2015)。随着林木根系直径的增加, 养分浓度 (如N、P含量) 降低, 导致不同径级根系分解速率不 同(Silver \& Miya, 2001; Ludovici \& Kress, 2006), 这 可能影响后续腐殖化进程。细根分解产物是一种潜 在的碳源, 而粗根分解主要取决于气候变化, 尤其 是温度的影响(Zhang \& Wang, 2015)。在高寒地区, 碳周转较慢, 且季节性雪被和冻融作用对根系分解 有重要影响(Henry, 2008), 这可能影响植物不同直 径根系腐殖化过程。虽然一些研究已经表明, 细根 和粗根形态、养分含量、功能和分解机制显著不同 (Guo et al., 2004; Aulen et al., 2011; Goebel et al.,
2011; Olajuyigbe et al., 2012), 但细根和粗根在不同 气候条件下的腐殖质累积特征在很大程度上仍然是 未知的。

川西亚高山森林地处青藏高原东缘，在调节区 域气候、保持水土和保育生物多样性等方面具有重 要的作用(Yang et al., 2005; 邓仁菊等, 2009)。常年 的低温和频繁的地质活动, 造成川西亚高山森林土 壤发育缓慢(Yang et al., 2005)。已有研究表明，川西 亚高山植物根系分布主要集中于表层土壤(胡建利 等, 2009), 该层土壤是有机质形成和腐殖化最为活 跃的层次。因此, 根系腐殖化对该区域森林土壤有 机质形成具有重要意义。前期研究表明, 冬季雪被 显著影响调落叶腐殖质累积(倪祥银等, 2014b), 且 这种影响在冬季和生长季节明显不同(Ni et al., 2015), 但并未关注根系腐殖化过程中不同根系直 径的胡敏酸和富里酸累积的变化格局。因此, 本研 究在前期研究基础上, 初步研究了川西亚高山森林 两种优势林木粗枝云杉(Picea asperata) 和岷江冷杉 (Abies faxoniana) 不同径级根系 $(0-2 、 2-5$ 和 $5-10 \mathrm{~mm})$ 在两年腐殖化过程中胡敏酸和富里酸在冬季和生长 季节的累积特征, 为进一步了解川西亚高山森林生 态系统地下碳循环过程提供基础数据。

\section{1 材料和方法}

\section{1 研究区域概况}

研究区域位于四川农业大学高山森林生态系统 定位研究站 $\left(31.23^{\circ}-31.32^{\circ} \mathrm{N}, 102.88^{\circ}-102.95^{\circ} \mathrm{E}\right.$, 海拔2 458-4 619 m)。地处青藏高原东缘褶皱带最外 缘部分, 具有典型的高山峡谷地貌, 属丹巴-松潘半 湿润气候。区域内年平均气温为 $2-4{ }^{\circ} \mathrm{C}$, 全年最高气 温 $23.7{ }^{\circ} \mathrm{C}$ (在7月), 最低气温 $-18{ }^{\circ} \mathrm{C}$ (在1月)。年降水 量为 $850 \mathrm{~mm}$ 。研究区域的土壤形成和发育过程缓慢, 土壤通常是雏形土和新成土, 以暗棕壤为主, 含较 多石砾; 地表调落物层较厚。该区域的优势乔木是粗 
枝云杉和岷江冷杉。

\section{2 野外采样和处理}

2013年8月, 在云冷杉混交林采集粗枝云杉和 岷江冷杉不同径级的根系。样地基本情况如下: 坡 度 $5^{\circ}$, 坡向 $\mathrm{NE} 46^{\circ}$, 土壤为暗棕壤。表层土壤有机碳 为 $88.5 \mathrm{~g} \cdot \mathrm{kg}^{-1}$, 全氮为 $5.5 \mathrm{~g} \cdot \mathrm{kg}^{-1}$, 全磷为 $0.5 \mathrm{~g} \cdot \mathrm{kg}^{-1}, \mathrm{pH}$ 值为6.3。在云冷杉混交林内设置 3 个 $100 \mathrm{~m} \times 100 \mathrm{~m}$ 的 样方, 在每个样方内选择胸径大小相似的粗枝云杉 和岷江冷杉目标树种, 之后在每棵树的树干基部 $2 \mathrm{~m}$ 左右范围内用铲子挖取 5 个 $50 \mathrm{~cm} \times 50 \mathrm{~cm} \times 20 \mathrm{~cm}$ (长 $\times$ 宽 $\times$ 高 $)$ 大小的土块, 收集土块中的树木根系。根 系采集主要采用手工挖掘法(Böhm, 1979), 在整个 采根的过程中尽量保持根系的完整性。清除死根(颜 色发暗且无弹性)和根表面的土壤及杂质后, 装入 封口袋, 于 $4{ }^{\circ} \mathrm{C}$ 保存。

将采回的根系取出，置于 40 目篮，在流水下洗 去表面土壤, 用牛皮纸小心吸干水分, 挑选完整的 根系。用游标卡尺测量根系直径, 按直径大小分为 3 个径级: 细根 $(0-2 \mathrm{~mm}) 、$ 中根 $(2-5 \mathrm{~mm})$ 和粗根(5-10 $\mathrm{mm})$ (Smit et al., 1999; 张秀娟等, 2006)。将分置好的 样品自然风干, 剪成 $3 \mathrm{~cm}$ 左右的根段, 称取各径级 根 $5.00 \mathrm{~g}$ 置于规格为 $20 \mathrm{~cm} \times 25 \mathrm{~cm}$, 上表面孔径为 $1 \mathrm{~mm}$ ，下表面 $0.5 \mathrm{~mm}$ 的凋落物袋内。于 2013 年 10 月 11日(生长季节末期), 在本研究样地内随机选取 3 个 均质样方 $(5 \mathrm{~m} \times 5 \mathrm{~m})$, 在每个样方内挖取 $10 \mathrm{~cm}$ 深的 土层, 将装好样品的调落物分解袋平铺于土层中, 之后小心覆盖之前挖出的土壤及枯枝落叶。将调落 袋用绳子串联, 做好标记, 以方便取样。根据前期研 究, 研究区域每年 10 月中旬至翌年5月为冬季, 5 月 中旬至10月中旬为生长季节(邓仁菊等, 2009), 因此, 本研究分别于 2014 年5月15日和10月17日、2015年5 月 22 日和 10 月 12 日进行采样。试验期间 $10 \mathrm{~cm}$ 土壤温 度采用纽扣式温度记录仪 (DS1921-F5\#, Maxim/ Dallas Semiconductor, Dallas, USA)测定(图1)。每次 在各样方内随机采集装有两树种 3 个径级根系的调 落物袋各 2 袋, 3 个样方共 6 袋。小心去除泥土杂物及 新生根系，分装于密封袋中带回实验室。

\section{3 室内分析}

将采集的样品风干、粉碎、过 100 目篮。胡敏酸、 富里酸的分离和提取参照《中华人民共和国林业行 业标准LY/T 1238-1999》。称取风干样品 $1.00 \mathrm{~g}$ 于 $150 \mathrm{~mL}$ 锥形瓶中, 加 $100 \mathrm{~mL} 0.1 \mathrm{~mol} \cdot \mathrm{L}^{-1} \mathrm{NaOH}$ 和

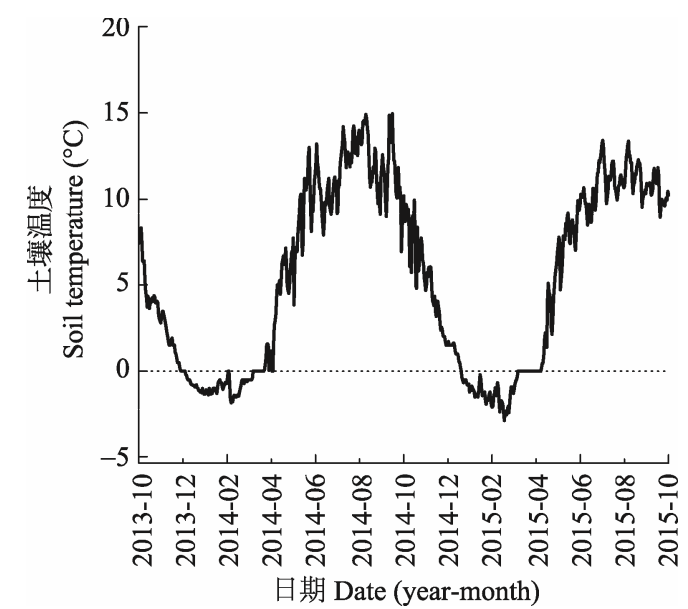

图1 试验期 $10 \mathrm{~cm}$ 土壤日平均温度动态。

Fig. 1 Daily soil temperature in $10 \mathrm{~cm}$ soil depth during the experimental period.

$0.1 \mathrm{~mol} \cdot \mathrm{L}^{-1} \mathrm{Na}_{4} \mathrm{P}_{2} \mathrm{O}_{7} \cdot 10 \mathrm{H}_{2} \mathrm{O}$ 混合提取液, 加塞振荡 $10 \mathrm{~min}$, 在无氧条件下于 $80{ }^{\circ} \mathrm{C}$ 水浴 $1 \mathrm{~h}$, 冷却后过滤, 滤液为待测液。将待测液于 $3000 \mathrm{r} \cdot \mathrm{min}^{-1}$ 离心 $10 \mathrm{~min}$, 过 $0.45 \mu \mathrm{m}$ 滤膜, 滤液为浸提液, 测定腐殖质。另取 待测液 $20 \mathrm{~mL}$ 于试管中, $80{ }^{\circ} \mathrm{C}$ 水浴, 逐滴加 $0.5 \mathrm{~mol} \cdot \mathrm{L}^{-1} \mathrm{H}_{2} \mathrm{SO}_{4}$ 至 $\mathrm{pH}=2$ (絮状沉淀), 于 $80{ }^{\circ} \mathrm{C}$ 水 浴 $30 \mathrm{~min}$, 无氧条件下静置过夜。用 $0.05 \mathrm{~mol} \cdot \mathrm{L}^{-1}$ $\mathrm{H}_{2} \mathrm{SO}_{4}$ 洗涤，过滤，沉淀即为胡敏酸。用热的 0.05 $\mathrm{mol} \cdot \mathrm{L}^{-1} \mathrm{NaOH}$ 少量多次洗涤沉淀, 过滤至 $100 \mathrm{~mL}$ 容 量瓶, 定容, 取溶解的胡敏酸溶液过 $0.45 \mu \mathrm{m}$ 滤膜, 测 定胡敏酸(Wang et al., 2010; Ni et al., 2015)。腐殖质、 胡敏酸含量用总有机碳分析仪 (multi N/C 2100, Analytik Jena, Jena, Germany)测定。

\section{4 数据处理和统计分析}

富里酸含量计算公式如下:

$C_{\mathrm{FA}}=C_{\mathrm{HC}}-C_{\mathrm{HA}}$

式中, $C_{\mathrm{HC}} 、 C_{\mathrm{HA}}$ 和 $C_{\mathrm{FA}}$ 分别为腐殖质、胡敏酸和富里 酸含量(倪祥银等, 2014b; Ni et al., 2015); 以胡敏 酸、富里酸含量与每次采样测得根系质量残留量的 乘积表示胡敏酸、富里酸累积量, 以两次采样日期 的胡敏酸、富里酸累积量之差表征该时期胡敏酸、 富里酸净累积量。以各采样日期胡敏酸/富里酸表征 胡敏酸、富里酸的相对含量和形成速度(Abakumov et al., 2013)。

采用重复测量方差分析检验不同时期、根系径 级、树种及其交互作用对胡敏酸、富里酸含量和净 累积量以及胡敏酸/富里酸的影响; 采用单因素方 差分析检验胡敏酸、富里酸含量和净累积量以及胡 敏酸/富里酸在同一树种不同径级之间的差异显著 
性。用Pearson相关分析比较分解两年后胡敏酸、富 里酸净累积量与基质品质的相关关系。以上分析采 用SPSS 17.0 (IBM SPSS Statistics, Chicago, USA) 完成。

\section{2 结果和分析}

\section{1 不同径级根系初始化学组分含量}

川西亚高山森林中粗枝云杉和岷江冷杉不同径 级根系 $(0-2 、 2-5$ 和 $5-10 \mathrm{~mm})$ 中的初始有机碳 $(\mathrm{C})$ 、 全氮 $(\mathrm{N})$ 、全磷 $(\mathrm{P})$ 、木质素、纤维素浓度及其比值 在不同径级和不同物种间差异显著(表1)。相同径级 根系的 $\mathrm{C}$ 浓度、 $\mathrm{C} / \mathrm{N} 、 \mathrm{C} / \mathrm{P}$ 、木质素、木质素 $\mathrm{N} 、$ 木 质素/P、木质素/纤维素表现为岷江冷杉>粗枝云杉; $\mathrm{N} 、 \mathrm{P}$ 浓度和纤维素表现为粗枝云杉>岷江冷杉。两 树种的 $\mathrm{C} 、 \mathrm{P}$ 浓度, $\mathrm{C} / \mathrm{N}, \mathrm{C} / \mathrm{P}$, 纤维素和木质素 $/ \mathrm{N}$ 在 径级间表现为粗根>中根>细根。相反, N浓度、木
质素和木质素/纤维素随径级增加而下降。

\section{2 不同径级根系胡敏酸含量和净累积量}

川西亚高山森林根系腐殖化过程中不同径级对 胡敏酸含量影响显著 $(p<0.05)$, 而径级和树种差异 对胡敏酸净累积量均无显著影响，但不同径级间有 一定的波动，时期与径级的交互作用显著 $(p<0.05)$ (表2)。经过两年的腐殖化分解，两树种不同径级根 系胡敏酸含量表现出在各个时期均随径级的增大而 显著减少 $(p<0.05)$ 的趋势(图 $2 \mathrm{~A}-2 \mathrm{~B})$ 。而胡敏酸均 净累积, 每 $5 \mathrm{~g}$ 粗枝云杉细根、中根和粗根中两年总 的净累积量为 $0.040 、 0.054 、 0.038 \mathrm{~g}$; 岷江冷杉为 $0.076 、 0.040 、 0.039 \mathrm{~g}($ 图3A-3B)。第一年冬季，两 树种不同径级根系胡敏酸表现出不同程度的降解, 且粗枝云杉根系胡敏酸净累积量随径级的增大而显 著增加 $(p<0.05)$; 生长季节, 两树种根系的胡敏酸 均累积, 随根系径级增大, 岷江冷杉胡敏酸净累积

表1 粗枝云杉和峮江冷杉不同径级根系的初始品质特征(平均值土标准误差, $n=3$ )

Table 1 Initial chemical quality in three root diameter classes of Picea asperata and Abies faxoniana $(\operatorname{mean} \pm S E, n=3)$

\begin{tabular}{|c|c|c|c|c|c|c|c|c|c|c|c|}
\hline $\begin{array}{l}\text { 物种 } \\
\text { Species }\end{array}$ & $\begin{array}{c}\text { 径级 } \\
\text { Diameter } \\
(\mathrm{mm})\end{array}$ & $\begin{array}{c}\text { 碳 } \\
\text { Carbon } \\
(\mathrm{C}) \\
\left(\mathrm{g} \cdot \mathrm{kg}^{-1}\right)\end{array}$ & $\begin{array}{c}\text { 氮 } \\
\text { Nitrogen } \\
(\mathrm{N}) \\
\left(\mathrm{g} \cdot \mathrm{kg}^{-1}\right)\end{array}$ & $\begin{array}{c}\text { 磷 } \\
\text { Phosphorus } \\
(\mathrm{P}) \\
\left(\mathrm{g} \cdot \mathrm{kg}^{-1}\right)\end{array}$ & $\begin{array}{c}\text { 碳氮比 } \\
\mathrm{C} / \mathrm{N}\end{array}$ & $\begin{array}{c}\text { 碳磷比 } \\
\mathrm{C} / \mathrm{P}\end{array}$ & $\begin{array}{c}\text { 木质素 } \\
\text { Lignin (\%) }\end{array}$ & $\begin{array}{c}\text { 纤维素 } \\
\text { Cellulose (\%) }\end{array}$ & $\begin{array}{c}\text { 木质素/N } \\
\text { Lignin/N }\end{array}$ & $\begin{array}{l}\text { 木质素/P } \\
\text { Lignin/P }\end{array}$ & $\begin{array}{l}\text { 木质素/纤维素 } \\
\text { Lignin/Cellulose }\end{array}$ \\
\hline \multirow{3}{*}{$\begin{array}{l}\text { 粗枝云杉 } \\
\text { Picea asperata }\end{array}$} & $0-2$ & $496.4 \pm 7.1$ & $5.6 \pm 0.4$ & $0.34 \pm 0.01$ & $89 \pm 4$ & $1450 \pm 33$ & $16 \pm 0.6$ & $28.9 \pm 6.9$ & $20.8 \pm 3.3$ & $51.7 \pm 3.5$ & $843 \pm 40$ \\
\hline & $2-5$ & $496.6 \pm 6.5$ & $4.2 \pm 0.2$ & $0.33 \pm 0.04$ & $118 \pm 5$ & $1538 \pm 139$ & $13 \pm 1.3$ & $26.1 \pm 3.4$ & $23.0 \pm 1.6$ & $62.0 \pm 2.3$ & $808 \pm 76$ \\
\hline & $5-10$ & $512.1 \pm 7.8$ & $2.6 \pm 0.2$ & $0.26 \pm 0.04$ & $195 \pm 18$ & $2022 \pm 291$ & $10 \pm 1.7$ & $25.9 \pm 6.6$ & $32.3 \pm 9.6$ & $98.7 \pm 6.3$ & $1022 \pm 128$ \\
\hline \multirow{3}{*}{$\begin{array}{l}\text { 岷江冷杉 } \\
\text { Abies faxoniana }\end{array}$} & $0-2$ & $498.8 \pm 20.0$ & $5.0 \pm 0.4$ & $0.32 \pm 0.01$ & $99 \pm 5$ & $1559 \pm 74$ & $16 \pm 1.5$ & $38.8 \pm 6.1$ & $16.2 \pm 5.7$ & $77.2 \pm 4.9$ & $1214 \pm 38$ \\
\hline & $2-5$ & $533.9 \pm 7.3$ & $3.8 \pm 0.6$ & $0.30 \pm 0.01$ & $144 \pm 19$ & $1760 \pm 44$ & $12 \pm 1.9$ & $34.7 \pm 10.8$ & $18.9 \pm 5.7$ & $93.6 \pm 12.9$ & $1142 \pm 19$ \\
\hline & $5-10$ & $540.9 \pm 13.3$ & $2.4 \pm 0.3$ & $0.23 \pm 0.04$ & $231 \pm 21$ & $2397 \pm 360$ & $10 \pm 0.8$ & $33.0 \pm 6.6$ & $32.8 \pm 9.7$ & $141.1 \pm 14.6$ & $1465 \pm 230$ \\
\hline 物种 Species (S) & & $* * *$ & $* * *$ & NS & $* * *$ & $* * *$ & $* * *$ & $* * *$ & $* * *$ & $* * *$ & $*$ \\
\hline 径级 Diameter (D) & & $* *$ & $* * *$ & $* * *$ & $* * *$ & $* * *$ & $* * *$ & $* * *$ & $* * *$ & $* *$ & $* *$ \\
\hline $\mathrm{S} \times \mathrm{D}$ & & $*$ & NS & NS & NS & $* * *$ & $*$ & $* * *$ & NS & NS & NS \\
\hline
\end{tabular}

双因素方差分析(NS, $p>0.05 ; *, p<0.05 ; * *, p<0.01 ; * * *, p<0.001)$ 。

Two-way ANOVA, Significant effects (NS, $p>0.05 ; *, p<0.05 ; * *, p<0.01 ; * * *, p<0.001$ ).

表2 不同分解时期、物种、径级对胡敏酸含量和净累积量、富里酸含量和净累积量以及胡敏酸/富里酸影响的重复测量方差分析结果

Table 2 Results of repeated measures ANOVA testing for the effects for date, tree species and root diameter on concentrations and net accumulations of humic acid and fulvic acid as well as on humic acid to fulvic acid ratio

\begin{tabular}{|c|c|c|c|c|c|}
\hline $\begin{array}{l}\text { 因子 } \\
\text { Factor }\end{array}$ & $\begin{array}{l}\text { 胡敏酸含量的 } F \text { 值 } \\
F \text { value for humic } \\
\text { acid concentration }\end{array}$ & $\begin{array}{c}\text { 胡敏酸净累积量的 } F \text { 值 } \\
F \text { value for net accumulations } \\
\text { of humic acid }\end{array}$ & $\begin{array}{c}\text { 富里酸含量的 } F \text { 值 } \\
F \text { value for fulvic acid } \\
\text { concentration }\end{array}$ & $\begin{array}{c}\text { 富里酸净累积量的 } F \text { 值 } \\
F \text { value for net accumulations } \\
\text { of fulvic acid }\end{array}$ & $\begin{array}{c}\text { 胡敏酸/富里酸的 } F \text { 值 } \\
F \text { value for humic acid } \\
\text { to fulvic acid ratio }\end{array}$ \\
\hline 时期 Date (T) & $97.950^{* * *}$ & $46.690^{* * *}$ & $366.440^{* * *}$ & $82.531^{* * *}$ & $146.677^{* * *}$ \\
\hline 树种 Species (S) & 0.067 & 0.356 & 0.154 & 0.001 & 1.123 \\
\hline 径级 Diameter (D) & $63.535^{* * *}$ & 1.079 & $37.853^{* * *}$ & $19.003^{* * *}$ & 1.146 \\
\hline 时期 $\times$ 物种 $\mathrm{T} \times \mathrm{S}$ & 1.270 & 0.899 & $4.519^{* *}$ & $4.622^{* *}$ & 2.266 \\
\hline 时期 $\times$ 径级 $T \times D$ & $5.054^{* *}$ & $2.704^{*}$ & $4.704^{* *}$ & 1.578 & 0.322 \\
\hline 物种 $\times$ 径级 $\mathrm{S} \times \mathrm{D}$ & 3.751 & 1.871 & $4.609^{*}$ & 0.710 & 1.145 \\
\hline $\begin{array}{l}\text { 时期 } \times \text { 物种 } \times \text { 径级 } \mathrm{T} \\
\times \mathrm{S} \times \mathrm{D}\end{array}$ & 1.642 & 1.272 & 2.141 & 2.348 & 0.532 \\
\hline
\end{tabular}

$*, p<0.05 ; * *, p<0.01 ; * * *, p<0.001$. 

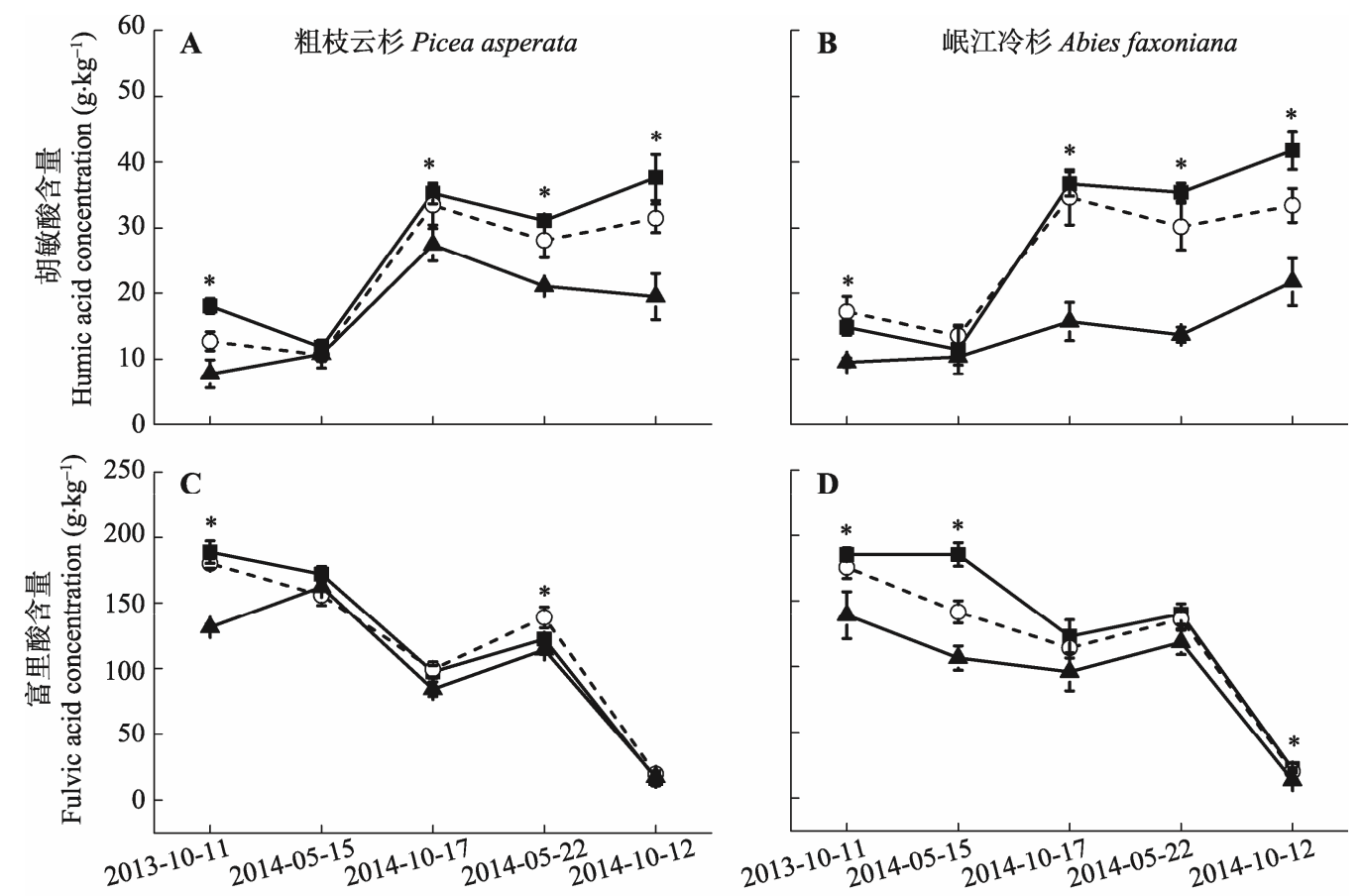

采样日期 Sampling date

$\longrightarrow 0-2 \mathrm{~mm} \quad--0-\cdot 2-5 \mathrm{~mm} \longrightarrow 5-10 \mathrm{~mm}$

图2 粗枝云杉和岷江冷杉不同径级根系在不同采样日期的胡敏酸和富里酸含量(平均值土标准误差, $n=3$ )。*, $p<0.05$ 。

Fig. 2 Concentrations of humic acid and fulvic acid in three root diameter classes of Picea asperata and Abies faxoniana on different sampling dates (mean $\pm S E, n=3$ ). ${ }^{*}, p<0.05$.

量显著减少 $(p<0.05)$ 。第二年, 两树种根系的胡敏 酸均表现出不同程度的降解, 但在生长季节胡敏酸 表现出不同程度的累积, 且不同径级间根系胡敏酸 净累积量差异不显著。经过两年的腐质化, 两树种 不同径级根系胡敏酸在冬季均降解, 生长季节均累 积。岷江冷杉和粗枝云杉在生长季节的累积量 $(0.25$ $\mathrm{g}$ 和 $0.26 \mathrm{~g})$ 分别大于冬季的降解量 $(0.10 \mathrm{~g}$ 和 $0.13 \mathrm{~g})$, 且在第一年生长季节的累积量 $(0.25 \mathrm{~g}$ 和 $0.20 \mathrm{~g})$ 分别 大于第二年生长季节的累积量 $(0.05 \mathrm{~g}$ 和 $0.01 \mathrm{~g})$ 。

\section{3 不同径级根系富里酸含量和净累积量}

川西亚高山森林根系腐殖化过程中不同径级显 著影响富里酸含量和净累积量 $(p<0.05)$, 但两个树 种之间无显著差异 (表2)。经过两年的腐殖化, 两树 种不同径级根系富里酸含量表现出在各个时期均随 径级的增大而显著减少 $(p<0.05)$ 的趋势 (图 2C-2D)。而富里酸总体表现为降解, 粗枝云杉细根、 中根和粗根降解量为 $0.89 、 0.83$ 和 $0.59 \mathrm{~g}$; 岷江冷杉 为 $0.85 、 0.80$ 和 $0.64 \mathrm{~g}$ 。富里酸净累积量在粗枝云杉 根系中表现为第一年冬季、整个第一年以及整个两 年研究阶段随径级的增大而显著增加 $(p<0.05)$ 的 趋势, 岷江冷杉根系中表现为第一年生长季节随径 级的增大而显著增加 $(p<0.05)$ (图3C-3D), 其余时
期两树种不同径级间差异不显著。第一年, 两树种 根系富里酸均降解, 粗枝云杉富里酸净累积量随径 级的增大而显著增加 $(p<0.05)$, 岷江冷杉富里酸净 累积量在不同径级间无显著差异。第二年, 两树种 根系富里酸均表现出不同程度的降解; 但在冬季, 两 树种不同径级根系富里酸均累积; 生长季节, 两树 种不同径级根系富里酸均降解, 不同径级根系富里 酸净累积量差异不显著。就整个研究阶段而言, 两 树种根系富里酸总体表现为降解。岷江冷杉和粗枝 云杉降解量 $(2.48$ 和 $2.62 \mathrm{~g})$ 分别大于净累积量 $(0.19$ 和 $0.32 \mathrm{~g})$, 且粗枝云杉两年的累积量随径级的增大而 显著 $(p<0.05)$ 增加。

\section{4 不同径级根系胡敏酸/富里酸比值}

川西亚高山森林根系腐殖化过程中胡敏酸/富 里酸总体上表现出随径级增大而减小的趋势, 除第 二年生长季节以外的所有时期胡敏酸/富里酸均小 于1 (图4)。第一年, 两树种根系胡敏酸/富里酸在不 同径级间差异不显著, 且冬季比生长季节小。第二 年生长季节, 粗枝云杉和岷江冷杉根系胡敏酸/富 里酸随径级增大而减少, 粗枝云杉细根、中根和粗 根胡敏酸/富里酸值分别为 $1.58 、 1.62 、 1.18$, 岷江冷 杉为 $1.92 、 1.68 、 1.80$, 远远高于冬季。就整个 


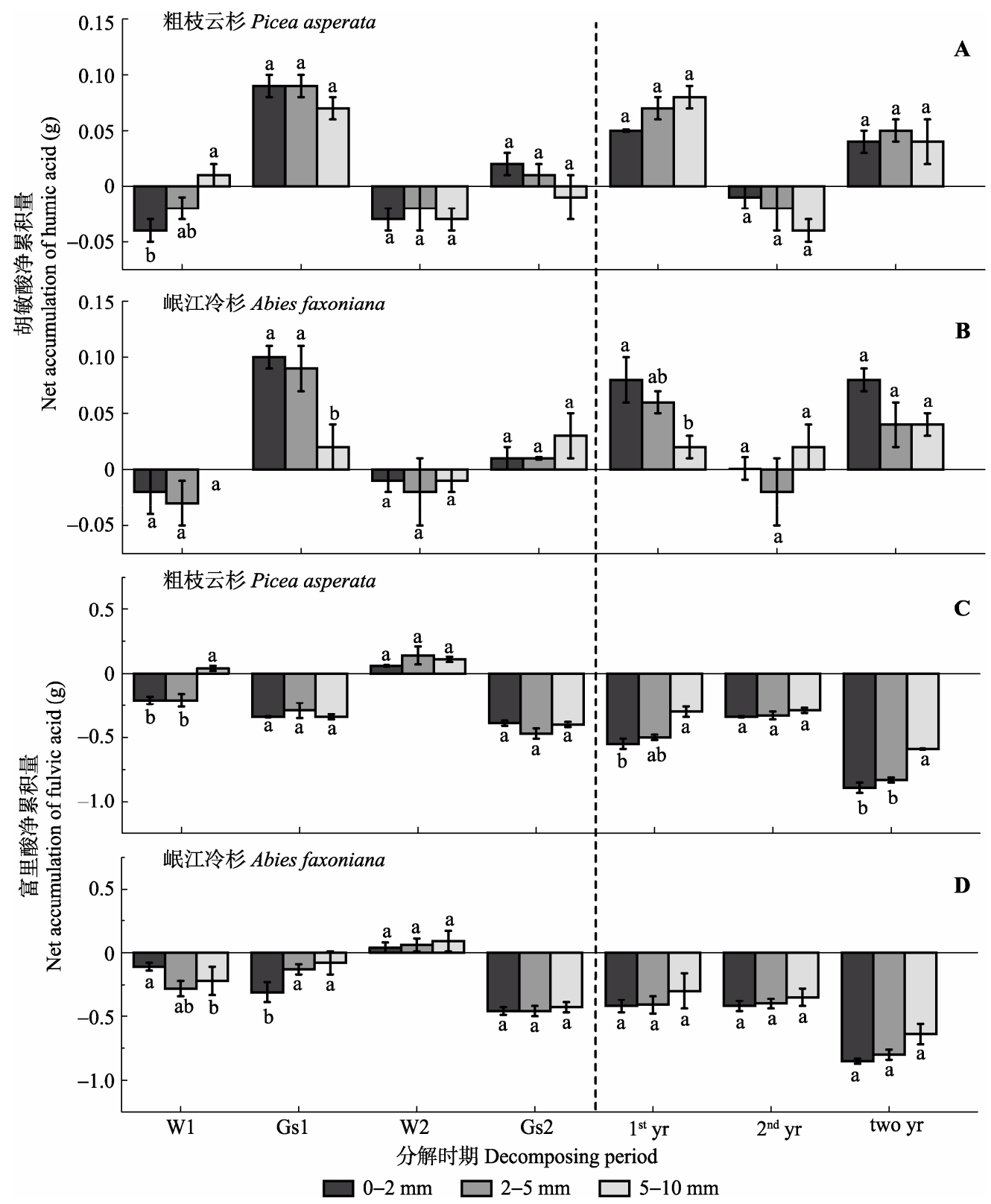

图3 粗枝云杉和岷江冷杉不同径级根系不同分解时期的胡敏酸、富里酸净累积量(平均值土标准误差, $n=3$ )。W1, 第一年冬 季; Gs1，第一年生长季节; W2，第二年冬季; Gs2，第二年生长季节; 1st yr，第一年; 2nd yr，第二年; two yr，两年。不同小写字 母表示在同一树种不同径级之间差异显著 $(p<0.05)$ 。

Fig. 3 Net accumulation of humic acid and fulvic acid in three root diameter classes of Picea asperata and Abies faxoniana during the winter and growing season (mean $\pm S E, n=3$ ). W1, the first winter; Gs1, the first growing season; W2, the second winter; Gs2, the second growing season; $1 \mathrm{st}$ yr, the first year; $2 \mathrm{nd}$ yr, the second year; two yr, two years. Different lowercase letters show significant differences among root diameter classes for the same tree species $(p<0.05)$.

研究期而言，第一年冬季和生长季胡敏酸/富里酸 分别小于第二年冬季和生长季。

\section{5 两年腐殖质净累积量与基质初始品质的关系}

相关分析(表3)表明, 分解两年后, 胡敏酸净累 积量与根系基质初始品质无显著相关关系 $(p>$ $0.05)$, 而富里酸净累积量与根系基质初始品质显著 相关 $(p<0.05)$ 。富里酸净累积量与根系基质初始 $\mathrm{N}$ 、 $\mathrm{P}$ 和木质素/纤维素显著负相关 $(p<0.05)$, 与纤维
素、 $\mathrm{C} / \mathrm{N} 、 \mathrm{C} / \mathrm{P}$ 和木质素/N极显著正相关 $(p<0.01)$ 。

\section{3 讨论}

已有研究表明, 植物根系分解与腐殖化密切相 关(Stevenson, 1994), Ciarkowska和Miech Wka (2017) 认为高 $\mathrm{C} / \mathrm{N}$ 影响腐殖质的形成, 腐殖化程度与 $\mathrm{N}$ 含 量增加密切相关(Kramer et al., 2003), Melillo等 (1982)发现分解速率与木质素 $/ \mathrm{N}$ 呈极显著的负相关 www.plant-ecology.com 


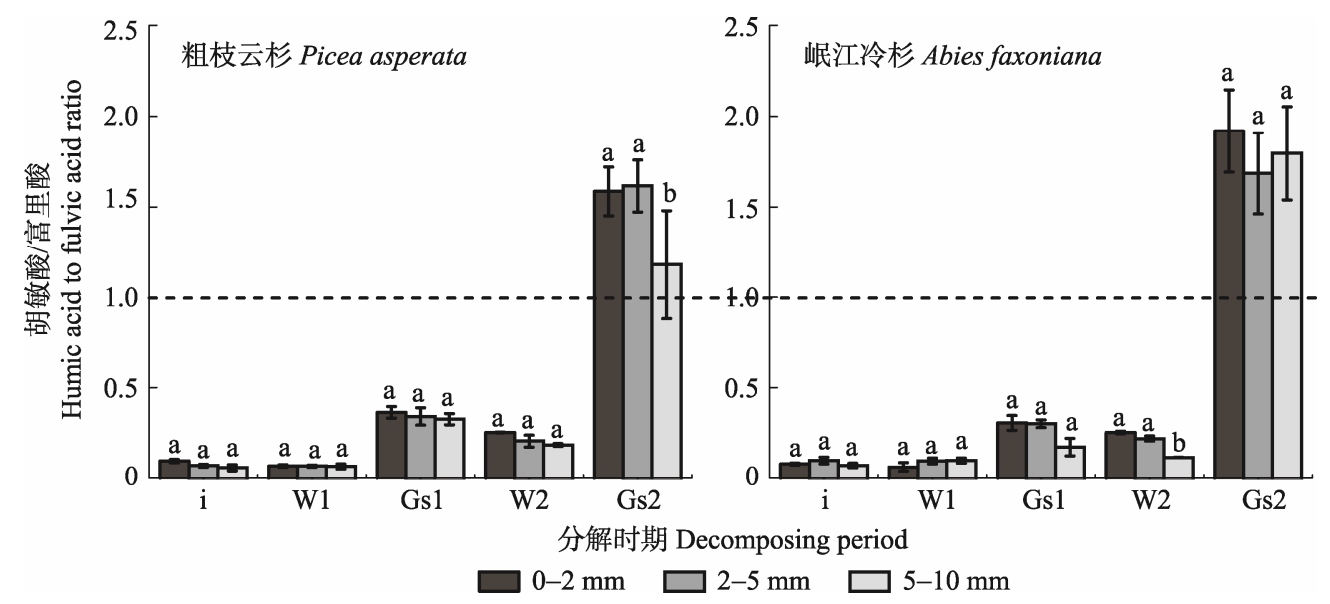

图4 粗枝云杉和岷江冷杉不同径级根系在不同分解时期的胡敏酸/富里酸(平均值土标准误差, $n=3$ )。 $\mathrm{i}$, 初始值; W1, 第一年 冬季; Gs1, 第一年生长季节; W2, 第二年冬季; Gs2, 第二年生长季节。不同小写字母表示在同一树种不同径级之间差异显著 $(p<0.05)$ 。

Fig. 4 Humic acid and fulvic acid in three root diameter classes of Picea asperata and Abies faxoniana during winter and growing season (mean $\pm S E, n=3$ ). i, initial; W1, the first winter; Gs1, the first growing season; W2, the second winter; Gs2, the second growing season. Different lowercase letters show significant differences among_root diameter classes for the same tree species $(p<$ $0.05)$.

表3 分解两年后胡敏酸和富里酸净累积量与初始基质品质的相关关系 Table 3 Relationships between the net accumulation of humic acid and fulvic acid and the initial root quality after 2-year decomposition

\begin{tabular}{lcc}
\hline $\begin{array}{l}\text { 初始品质 } \\
\text { Initial quality }\end{array}$ & $\begin{array}{c}\text { 胡敏酸净累积量 } \\
\text { Net accumulation } \\
\text { of humic acid }\end{array}$ & $\begin{array}{c}\text { 富里酸净累积量 } \\
\text { Net accumulation } \\
\text { of fulvic acid }\end{array}$ \\
\hline 碳 Carbon (C) & -0.276 & 0.402 \\
氮 Nitrogen (N) & 0.221 & $-0.805^{* *}$ \\
磷 Phosphorus (P) & 0.326 & $-0.664^{* *}$ \\
木质素 Lignin & 0.329 & -0.223 \\
纤维素 Cellulose & -0.302 & $0.760^{* *}$ \\
碳氮比 C/N ratio & -0.275 & $0.795^{* *}$ \\
碳磷比 C/P ratio & -0.172 & $0.632^{* *}$ \\
木质素/氮 Lignin/N & -0.141 & $0.664^{* *}$ \\
木质素/磷 Lignin/P & -0.068 & 0.344 \\
木质素/纤维素 Lignin/Cellulose & 0.381 & $-0.550^{*}$ \\
\hline$* p<0.05 ; * *, p<0.01 ; n=18$ & &
\end{tabular}

${ }^{*}, p<0.05 ; * *, p<0.01 ; n=18$.

关系。而细根 (直径 $<2 \mathrm{~mm}$ ) 和粗根(直径 $>2 \mathrm{~mm}$ ) 的分 解对土壤 $\mathrm{C}$ 及养分的输入贡献存在显著差异(Zhang \& Wang, 2015), 因此根系腐殖化过程中腐殖质含量 可能受植物根系径级影响。对川西亚高山森林粗枝 云杉和岷江冷杉根系腐殖化研究发现, 胡敏酸和富 里酸含量在各时期均随径级的增大而显著减少(图 2)。这可能是因为本研究中两树种根系 $\mathrm{N}$ 含量随径 级增大而降低(表1), 促进微生物作用生成腐殖质 (Cotrufo et al., 2013), 因此细根腐殖质含量更高。本 研究还发现, 胡敏酸净累积量在细根、中根和粗根 间差异不显著，但富里酸净累积量差异显著(表2)。 这可能是因为在根系腐殖化过程中, 较细的根含有
大量可溶性组分, 能被土壤微生物更有效地利用 (Cotrufo et al., 2013), 增强微生物聚合作用，易形 成分子量较小的富里酸(张夫道和Fokina, 1994), 导 致细根、中根和粗根的富里酸净累积量差异显著。 其次, 随腐殖化程度的加深, 富里酸转化为分子量 更大、结构更复杂的胡敏酸，其所需前体物质木质 素及其降解产物(窦森, 2010)增多。而前期研究发现, 根系径级在短期内对木质素降解的影响不明显(唐 仕姗等, 2015), 导致细根、中根和粗根供应给富里 酸转化为胡敏酸的底物浓度无显著差异, 因此根系 径级对胡敏酸净累积量的影响不显著。

不同树种根系化学组成存在差异(靳贝贝和国 庆喜, 2013), 影响腐殖质形成。但本研究中, 胡敏 酸、富里酸含量和净累积量在两树种间差异不显著, 主要是因为粗枝云杉和岷江冷杉均为针叶树种, 木 质素及养分释放特征相同(唐仕姗等, 2015)。而木质 素作为腐殖质形成的重要前体物质, 侧链经氧化可 生成构成腐殖质核心骨架的木质素类衍生物(Amir et al., 2006); 根系分解释放的养分供微生物腐质化 活动。因此, 本研究两针叶树种腐殖质累积特征差 异不显著。

本研究中, 根系腐殖质累积在冬季和生长季节 存在差异。胡敏酸和富里酸在冬季均降解。首先根 系在腐殖化前期, 恰逢高寒地区冻融季节, 气温急 剧下降并伴随雪被的形成、覆盖和融化，局域微环 境水热条件发生剧烈变化(吴彦和Onipcenko, 2007), 
抑制微生物活性, 腐殖质形成受阻。其次, 初期快速 形成的腐殖质结构不稳定, 强烈的冻融作用可能促 进胡敏酸和富里酸降解(Wetterstedt et al., 2010)。然 而, 生长季胡敏酸累积, 富里酸降解。一方面, 生长 季土壤动物生命活动增强, 通过对根系的取食等物 理破碎过程(刘瑞龙等, 2013), 使根系结构更有利于 微生物的附着; 另一方面, 因降水量增多, 温度升 高, 根中大量可溶性物质(氮、磷和可溶性碳等)淋洗 入土壤, 有利于提高土壤微生物基质利用效率 (Cotrufo et al., 2013), 促进微生物参与根系腐殖化 过程。另外, 生长季节微生物活动旺盛(Schimel et al., 2004), 代谢产生的单体产物经聚合反应也能形 成腐殖质(Amir et al., 2006)。但因降水量增多, 累积 的酸溶性富里酸淋溶流失(Elliott, 2013)。同时, 随着 腐殖化进程的推进, 富里酸转化为胡敏酸(张夫道 和Fokina, 1994), 最终导致生长季节胡敏酸累积, 富里酸降解。此外, 本研究两个生长季胡敏酸累积 量表现出一定的差异, 可能是因为在分解过程中, 矿化与腐殖化伴随发生(Aber \& Melillo, 1991)。在第 一年生长季, $\mathrm{N} 、 \mathrm{P}$ 等易分解组分通过矿化释放 (Coûteaux et al., 1995; Hobbie, 2008), 为微生物参与 腐殖化提供底物, 促进微生物代谢转化与腐殖质前 体物质的形成, 最终促进腐殖质累积(Cotrufo et al., 2013; Berg \& McClaugherty, 2014)。到第二年生长季, 根系基质品质发生改变, $\mathrm{N} 、 \mathrm{P}$ 等养分在第一年已大 量释放(唐仕妌, 2016), 抑制微生物代谢转化作用, 腐殖质累积量减少, 因此两个生长季富里酸累积量 存在一定差异。

胡敏酸/富里酸表征腐殖质的组成情况(窦森等, 2007), 反映了胡敏酸、富里酸的相对形成速度 (Abakumov et al., 2013), 胡敏酸/富里酸小于1, 表 明在腐殖化过程中可能先形成富里酸(倪祥银等, 2014b)。本研究发现, 川西亚高山森林根系腐殖化 过程中两种林木 3 个径级的胡敏酸/富里酸总体上表 现出随径级增大而减小的趋势, 除第二年生长季节 以外的所有时期胡敏酸/富里酸均小于 1 (图4)。这是 因为: 一方面, 在腐殖质形成初期, 分解产生的非 结构性物质转化为富里酸的速率远大于胡敏酸的形 成速率(张夫道和Fokina, 1994); 另一方面, 新形成 的胡敏酸芳香环缩合程度低, 结构不稳定, 易转变 为富里酸(刘小虎等, 1999), 造成胡敏酸含量较低。 此外, 本研究发现, 第一年冬季和生长季胡敏酸/富
里酸分别小于第二年冬季和生长季, 第二年生长季 胡敏酸/富里酸大于 1 且表现出随径级增大显著 $(p<$ 0.05)减小。表明随腐殖化进程的推进, 腐殖质的芳 香缩合程度增高, 腐殖质结构趋于复杂化(Tuomela et al., 2000), 富里酸逐步转化成胡敏酸(Ponge \& Chevalier, 2006)。郝晓地等(2017)的研究也表明随处 理时间增加, 腐殖质的芳香度增加, 微生物对腐殖 质的降解难度增大。

在该区域的前期研究中发现，枯立木、大枯枝 和倒木胡敏酸和富里酸含量随腐烂等级增加而增加 (刘辉等, 2015), 而本研究中根系随腐殖化进程推进, 胡敏酸含量增加, 富里酸含量减少。可能是因为粗 木质残体直径均 $\geqslant 10 \mathrm{~cm}$ (刘辉等, 2015), 而本研究 根系直径最大范围为 5-10 mm, 根系比根长和比根 面积较粗木制残体大, 与动物和微生物接触的机会 多, 形成腐殖质的前体物质可能累积较少, 胡敏酸 和富里酸形成缓慢(周蛟等, 2017)。随着腐殖化进程 推进, 富里酸逐步转化为胡敏酸(张夫道和Fokina, 1994), 导致在根系腐殖化中胡敏酸和富里酸含量 变化不一致。倪祥银等(2014a)在研究该区域调落叶 腐殖化过程中发现, 冬季调落叶腐殖化与 $\mathrm{C} / \mathrm{N}$ 极显 著负相关。而本研究中, 分解两年后, 根系胡敏酸净 累积量与 $\mathrm{C} / \mathrm{N}$ 无显著相关, 富里酸净累积量与 $\mathrm{C} / \mathrm{N}$ 极显著正相关(表3), 表明基质品质显著影响腐殖质 的形成, 但不同调落物组分, 其基质品质影响腐殖 质形成的机制不同。

\section{4 结论}

川西亚高山森林中岷江冷杉和粗枝云杉的根系 在两年的腐殖化过程中, 胡敏酸、富里酸在不同时 期均表现出随根系径级的增大而减少的趋势, 富里 酸净累积量在不同径级间差异显著, 而胡敏酸净累 积量差异不显著; 胡敏酸、富里酸的含量和净累积 量在岷江冷杉和粗枝云杉间差异不显著。同时, 两 树种不同径级根系中胡敏酸在冬季降解在生长季累 积, 且第一年生长季胡敏酸累积量显著大于第二年 生长季, 但富里酸总体表现为降解。分解两年后, 胡 敏酸净累积量与根系基质初始品质无显著相关关系, 而富里酸净累积量与根系基质初始品质显著相关。

基金项目国家自然科学基金(31570601和 31570445)、国家重点研发计划(2016YFC0502505和 
2017YFC0505003)、四川省教育厅重点基金(17ZA0321) 和中国博士后科学基金项目(2014T70880)。

\section{参考文献}

Abakumov EV, Cajthaml T, Brus J, Frouz J (2013). Humus accumulation, humification, and humic acid composition in soils of two post-mining chronosequences after coal mining. Journal of Soils and Sediments, 13, 491-500.

Aber JD, Melillo JM (1991). Terrestrial Ecosystems. Saunders College Publication, Philadelphia.

Amir S, Hafidi M, Lemee L, Merlina G, Guiresse M, Pinelli E, Revel JC, Bailly JR, Ambles A (2006). Structural characterization of humic acids, extracted from sewage sludge during composting, by thermochemolysis-gas chromatographymass spectrometry. Process Biochemistry, 41, 410-422.

Asli S, Neumann PM (2010). Rhizosphere humic acid interacts with root cell walls to reduce hydraulic conductivity and plant development. Plant and Soil, 336, 313-322.

Aulen M, Shipley B, Bradley R (2011). Prediction of in situ root decomposition rates in an interspecific context from chemical and morphological traits. Annals of Botany, 109, 287-297.

Berg B, McClaugherty C (2014). Plant Litter: Decomposition, Humus Formation, Carbon Sequestration. 3rd edn. Springer-Verlag, Berlin. 11-15.

Böhm W (1979). Methods of Studying Root Systems. SpringerVerlag, Berlin.

Chien SW, Wang MC, Hsu JH, Seshaiah K (2006). Influence of fertilizers applied to a paddy-upland rotation on characteristics of soil organic carbon and humic acids. Journal of Agricultural and Food Chemistry, 54, 6790-6799.

Ciarkowska K, Miech Wka A (2017). The role of bilberry and alpine lady-fern in soil formation within the Carpathian subalpine spruce forest stands. Geoderma, 305, 162-172.

Cotrufo MF, Wallenstein MD, Boot CM, Denef K, Paul E (2013). The Microbial Efficiency-Matrix Stabilization (MEMS) framework integrates plant litter decomposition with soil organic matter stabilization: Do labile plant inputs form stable soil organic matter? Global Change Biology, 19, 988-995.

Coûteaux MM, Bottner P, Berg B (1995). Litter decomposition, climate \& litter quality. Trends in Ecology and Evolution, 10, 63-66.

Deng RJ, Yang WQ, Feng RF, Hu JL, Qin JL, Qiong XJ (2009). Mass loss and element release of litter in the subalpine forest over one freeze-thaw season. Acta Ecologica Sinica, 29, 5730-5735. (in Chinese with English abstract) [邓仁菊, 杨万勤, 冯瑞芳, 胡建利, 秦嘉 励, 熊雪晶 (2009). 季节性冻融期间亚高山森林调落物 的质量损失及元素释放. 生态学报, 29, 5730-5735.]

Dou S (2010). Soil Organic Matter. Science Press, Beijing. 84. (in Chinese) [窦森 (2010). 土壤有机质. 科学出版社, 北京. 84.]

Dou S, Yu SQ, Zhang JJ (2007). Effects of carbon dioxide concentration on humus formation in cornstalk decomposition. Acta Pedologica Sinica, 44, 458-466. (in Chinese with English abstract) [窦森, 于水强, 张晋京 (2007). 不同 $\mathrm{CO}_{2}$ 浓度对玉米秸秆分解期间土壤腐殖质形成的 影响. 土壤学报, 44, 458-464.]

Elliott J (2013). Evaluating the potential contribution of vegetation as a nutrient source in snowmelt runoff. Canadian Journal of Soil Science, 93, 435-443.

Goebel M, Hobbie SE, Bulaj B, Zadworny M, Archibald DD, Oleksyn J, Reich PB, Eissensstat DM (2011). Decomposition of the finest root branching orders, linking belowground dynamics to fine-root function and structure. Ecological Monographs, 81, 89-102.

Guo DL, Mitchell RJ, Hendricks JJ (2004). Fine root branch orders respond differentially to carbon source-sink manipulations in a longleaf pine forest. Oecologia, 140, 450-456.

Hao XD, Zhou P, Cao YL (2017). Origins and evolution processes of humic substances in wastewater treatment. Chinese Journal of Environmental Engineering, 11, 1-11. (in Chinese with English abstract) [郝晓地, 周鹏, 曹亚莉 (2017). 污水处理中腐殖质的来源及其演变过程. 环境 工程学报, 11, 1-11.]

Henry (2008). Climate change and soil freezing dynamics: Historical trends and projected changes. Climatic Change, $87,421-434$.

Hobbie SE (2008). Nitrogen effects on decomposition: A five-year experiment in eight temperate sites. Ecology, 89, 2633-2644.

Hu JL, Yang WQ, Zhang J, Deng RJ (2009). Characteristics of biomass and carbon stock of fir and birch fine roots in subalpine forest of western Sichuan, China. Chinese Journal of Applied \& Environmental Biology, 15, 313-317. (in Chinese with English abstract) [胡建利, 杨万勤, 张 健, 邓仁菊 (2009). 川西亚高山冷杉和白桦细根生物量 与碳储量特征. 应用与环境生物学报, 15, 313-317.]

Jin BB, Guo QX (2013). Root decomposition and nutrient dynamics of Quercus mongolica and Betula platyphylla. Acta Ecologica Sinica, 33, 2416-2424. (in Chinese with English abstract) [靳贝贝, 国庆喜 (2013). 蒙古柇、白桦根 系分解及养分动态. 生态学报, 33, 2416-2424.]

Kramer MG, Sollins P, Sletten RS, Swart PK (2003). N isotope fractionation and measures of organic matter alteration during decomposition. Ecology, 84, 2021-2025.

Lehmann J, Kleber M (2015). The contentious nature of soil organic matter. Nature, 528, 60-68.

Liu H, Yang WQ, Ni XY, Xiao S, Wu FZ (2015). Characters of different type of coarse woody debris humification in an 
alpine forest. Ecology and Environmental Sciences, 24, 1143-1149. (in Chinese with English abstract) [刘辉, 杨 万勤, 倪祥银, 肖酒, 吴福忠 (2015). 高山森林不同类 型粗木质残体腐殖化特征. 生态环境学报, 24 , 1143-1149.]

Liu RL, Yang WQ, Tan B, Wang WJ, Ni XY, Wu FZ (2013). Effects of soil fauna on $\mathrm{N}$ and $\mathrm{P}$ dynamics at different stages during the first year of litter decomposition in subalpine and alpine forests of western Sichuan. Chinese Journal of Plant Ecology, 37, 1080-1090. (in Chinese with English abstract) [刘瑞龙, 杨万勤, 谭波, 王文君, 倪祥 银, 吴福忠 (2013). 土壤动物对川西亚高山和高山森林 调落叶第一年不同分解时期 $\mathrm{N}$ 和 $\mathrm{P}$ 元素动态的影响. 植 物生态学报, 37, 1080-1090.]

Liu XH, Zou DY, Kang XF, Cheng YL, Wang HY, Zhou CJ, Wang SX (1999). The effect of persistent rotation fertilization on dynamic change in humic acid of brown earth. Chinese Journal of Soil Sciences, 30, 68-70. (in Chinese) [刘小虎, 邹德乙, 康笑峰, 程艳丽, 王洪岩, 周崇峻, 王绍新 (1999). 长期轮作施肥对棕壤腐殖酸动态变化 的影响. 土壤通报, 30, 21-23.]

Ludovici KH, Kress LW (2006). Decomposition and nutrient release from fresh and dried pine roots under two fertilizer regimes. Canadian Journal of Forest Research, 36, $105-111$.

Makita N, Kawamura A, Osawa A (2015). Size-dependent morphological and chemical property of fine root litter decomposition. Plant and Soil, 393, 283-295.

Melillo JM, Aber JD, Muratore JF (1982). Nitrogen and lignin control of hardwood leaf litter decomposition dynamics. Ecology, 63, 621-626.

Ni XY, Yang WQ, Li H, Xu LY, He J, Wu FZ (2014a). Effects of snowpack on early foliar litter humification during winter in a subalpine forest of western Sichuan. Chinese Journal of Plant Ecology, 38, 540-549. (in Chinese with English abstract) [倪祥银, 杨万勤, 李晗, 徐李亚, 何洁, 吴福忠 (2014a). 雪被斑块对川西亚高山森林6种调落 叶冬季腐殖化的影响. 植物生态学报, 38, 540-549.]

Ni XY, Yang WQ, Tan B, He J, Xu LY, Li H, Wu FZ (2015). Accelerated foliar litter humification in forest gaps: Dual feedbacks of carbon sequestration during winter and the growing season in an alpine forest. Geoderma, s241-242, $136-144$.

Ni XY, Yang WQ, Xu LY, He J, Li H, Wu FZ (2014b). Effects of winter snowpack on accumulation of humic acid and fulvic acid during humification of foliar litters in an alpine forest. Acta Pedologica Sinica, 51, 1138-1152. (in Chinese with English abstract) [倪祥银, 杨万勤, 徐李亚, 何 洁, 李晗, 吴福忠 (2014b). 雪被斑块对高山森林调落 叶腐殖化过程中胡敏酸和富里酸累积的影响. 土壤学 报, 51, 1138-1152.]

Olajuyigbe S, Tobin B, Hawkins M, Nieuwenhuis M (2012).
The measurement of woody root decomposition using two methodologies in a Sitka spruce forest ecosystem. Plant and Soil, 360, 77-91.

Ponge JF, Chevalier R (2006). Humus index as an indicator of forest stand and soil properties. Forest Ecology and Management, 233, 165-175.

Prescott CE, Maynard DG, Laiho R (2000). Humus in northern forests: Friend or foe? Forest Ecology and Management, $133,23-36$.

Schimel JP, Bilbrough C, Welker JM (2004). Increased snow depth affects microbial activity and nitrogen mineralization in two Arctic tundra communities. Soil Biology \& Biochemistry, 36, 217-227.

Silver WL, Miya RK (2001). Global patterns in root decomposition: Comparisons of climate and litter quality effects. Oecologia, 129, 407-419.

Smit AL, George E, Groenwold J (1999). Root observations and measurements at (transparent) interfaces with soil. In: Smit AL, Bengough AG, Engels C, Noordwijk MV, Pellerin S, vande Geijn SC eds. Root Methods. SpringerVerlag, New York. 236-266.

Stevenson FJ (1994). Humus Chemistry: Genesis, Composition, Reactions. 2nd edn. John Wiley \& Sons, New York. 17.

Tang SH (2016). Root Decomposition of Different Diameters of Three Dominant Subalpine Trees and Its Responses to Experimental Warming in the Western Sichuan. Master degree dissertation, Sichuan Agricultural University, Chengdu. (in Chinese with English abstract) [唐仕姗 (2016). 川西亚高山3 种优势林木不同径级根系分解及 其对模拟增温的响应. 硕士学位论文, 四川农业大学, 成都.]

Tang SH, Yang WQ, He W, Wang HP, Xiong L, Nie FY, Xu ZF (2015). Root decomposition, lignin and cellulose degradation of three dominant subalpine trees of different diameters in western Sichuan. Chinese Journal of Applied \& Environmental Biology, 21, 754-761. (in Chinese with English abstract) [唐仕姗, 杨万勤, 何伟, 王海鹏, 熊莉, 聂富育, 徐振锋 (2015). 川西亚高山3 种优势林木不同 径级根系分解及木质素、纤维素降解特征. 应用与环境 生物学报, 21, 754-761.]

Tuomela M, Hatakka A, Itavaara MVM (2000). Biodegradation of lignin in a compost environment: A review. Bioresource Technology, 72, 169-183.

Wang H, Hong YT, Lin QH, Hong B, Zhu YX, Wang Y, Xu H (2010). Response of humification degree to monsoon climate during the Holocene from the Hongyuan peat bog, eastern Tibetan Plateau. Palaeogeography, 286, 171-177.

Wetterstedt JÅM, Persson T, Ågren GRI (2010). Temperature sensitivity and substrate quality in soil organic matter decomposition: Results of an incubation study with three substrates. Global Change Biology, 16, 1806-1819.

Wu Y, Onipcenko VG (2007). The impact of snow-cover on

www.plant-ecology.com 
alpine vegetation type of different aspects in the west of Sichuan Province. Acta Ecologica Sinica, 27, 5120-5129. (in Chinese with English abstract) [吴彦, Onipcenko VG (2007). 雪被对川西高山植被坡向性分异的影响. 生态 学报, 27, 5120-5129.]

Yang WQ, Wang KY, Kellomki S, Gong HD (2005). Litter dynamics of three subalpine forests in western Sichuan. Pedosphere, 15, 653-659.

Zhang FD, Forkin AD (1994). Study on the decomposition and transformation of crop straws $\mathrm{C}$ in soils (in Chinese). Plant Nutrition and Fertilizer Science, 1, 27-38. (in Chinese with English abstract) [张夫道, Fokina D (1994). 作物秸 秆碳在土壤中分解和转化规律的研究. 植物营养与肥 料学报, 1, 27-38.]

Zhang XJ, Wu C, Mei, L, Han YZ, Wang ZQ (2006). Root decomposition and nutrient release of Fraxinus manshurica and Larix gmelinii plantations. Chinese Journal of
Applied Ecology, 17, 1370-1376. (in Chinese with English abstract) [张秀娟, 吴楚, 梅莉, 韩有志, 王政权 (2006). 水曲柳和落叶松人工林根系分解与养分释放. 应用生 态学报, 17, 1370-1376.]

Zhang XY, Wang W (2015). The decomposition of fine and coarse roots: Their global patterns and controlling factors. Scientific Reports, 5, 9940. doi: 10.1038/srep09940.

Zhou J, Yang WQ, Wu FZ, Tan B, Duan F, Liu H (2017). Dynamics on humic acid and fulvic acid in the stump systems with different log years in the Pinus massoniana plantations. Journal of University of Chinese Academy of Sciences, 34, 521-528. (in Chinese with English abstract) [周 蛟, 杨万勤, 吴福忠, 谭波, 段斐, 刘辉 (2017). 不同采 伐年限马尾松人工林伐桩的胡敏酸和富里酸动态特征. 中国科学院大学学报, 34, 521-528.]

责任编委: 陈世苹 责任编辑: 王 葳

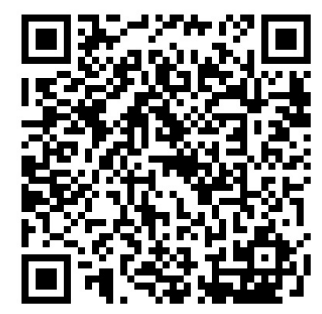

扫码向作者提问 